http://dx.doi.org/10.18232/alhe.972

Artículos

\title{
Créditos y fortunas: el caso de Juan Antonio Moldes en la Salta de fines del siglo XVIII
}

\section{Loans and Wealth: The Case of Juan Antonio Moldes in Salta by the end of the Eighteenth Century}

\author{
Marcelo G. Anachuri ${ }^{1}$ * DD 0000-0002-4127-2665 \\ ${ }^{1}$ Consejo de Investigación de la Universidad Nacional de Salta, Salta Capital, Argentina. \\ * Correspondencia: gabrielanachuri2016@gmail.com
}

Resumen. Este artículo se propone reconocer la incidencia y relevancia que tuvo la actividad de prestamista en la concreción de la fortuna y en el vertiginoso ascenso social de Juan Antonio Moldes durante la segunda mitad del siglo xviII. El acceso a nueva documentación permite exhibir hoy con detenimiento la exitosa actividad financiera desplegada por este hombre de quien la historiografía mucho dijo y escasamente indagó. El análisis de licencias de embarques, correspondencias privadas, libros notariales y testamentos muestran el éxito económico y el prestigio social alcanzado por Moldes en la sociedad virreinal salteña, al punto que pudo ocultar, hasta hoy, la condición de criado bajo la cual emigró de su Galicia natal.

Palabras clave: historia económica; préstamos; comerciantes; riqueza; crédito.

Abstract. This article aim at recognize incidents and relevance of the activity of lender in the concretion of fortune and the vertiginous social promotion of Juan Antonio Moldes during the second half of the eighteenth century. The access to new documentation allows to exhibit today with greater care the successful financial activity displayed by the man of whom the historiography much said and scarcely inquire into. The

CÓMO CITAR: Anachuri, M. G. (2019). Créditos y fortunas: el caso de Juan Antonio Moldes en la Salta de fines del siglo XVIII. América Latina en la Historia Económica, 26(3), e972. DOI: 10.18232/alhe.972

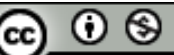

Esta obra está protegida bajo una Licencia Creative Commons Atribución-NoComercial 4.0 Internacional
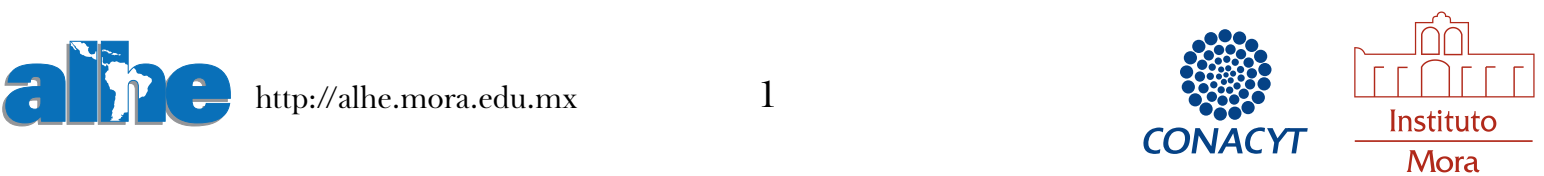
analysis of boarding licenses, private correspondence, books of writings and testament, show the economic success and the social prestige reached by Moldes in the viceregal society of Salta, to the point that he was able to hide until today the condition of servant under which he emigrated from his Galicia native.

Key words: economic history; loan; merchant; wealth; loans.

JEL: N860.

Recibido: 17 de marzo de 2018.

Aceptado: 14 de junio de 2018.

Publicado: 22 de marzo de 2019.

Organismo colaborador: Consejo de Investigaciones, Universidad Nacional de Salta (CIUNSA). Proyecto Tipo A/2340.

\section{INTRODUCCIÓN}

El crédito es una de las facetas, de la vida económica tardovirreinal salteña, menos abordada por las investigaciones de historia económica. Los estudios centraron su atención en la producción rural y el comercio ganadero hacia el Alto Perú, actividades señaladas como las más lucrativas de la época (Acevedo, 1965, pp. 223-318; Frías, 1924, pp. 88-139; Mata, 2000, pp. 181-242; Paz, 1999; Sánchez-Albornoz, 1965, pp. 305-312). Desde esta perspectiva, el préstamo fue analizado en relación con las fluctuaciones y vaivenes de las remesas de ganado mular, que desde Salta se hicieron al polo minero del Alto Perú. La actividad fue entendida como una respuesta a la falta de circulante generalmente impulsada por los comerciantes de larga distancia (Mata, 1996).

Uno de los rasgos de esta historiografía local, que renovó su utillaje teórico y metodológico una vez recuperada la democracia en 1983, es el uso de la categoría analítica de región, el énfasis en la explotación de la tierra como fuente generadora de riquezas y distancias sociales (Justiniano y Tejerina, 2012). El modo de historiar el pasado salteño impidió reconocer otras alternativas de generación de riquezas para los actores de la época en particular y para la economía salteña en general.

El crédito, definido por historiadores económicos y economistas como el intercambio de dos prestaciones separadas en el tiempo (Braudel, 2014, pp. 31 y ss.), cualquier transferencia de bienes, servicios, dinero a cambio de una promesa de pago en el futuro (Seldon y Pennance, 1983, pp. 167-168) relación social e histórica y condición previa que habilitaba a la operación económica (Wasserman, 2018, pp. 23, 287) ocupó un lugar significativo en las finanzas salteña tardovirreinales.

Fue la base sobre la cual se fortaleció esa estructura económica, financió las principales actividades productivas, sostuvo la circulación comercial en sus distintos niveles (local, transregional y transoceánico) y posibilitó el consumo cotidiano. Garantizó beneficios potenciales aquellos actores que invirtieron parte de sus activos en él. 
Juan Antonio Moldes es un caso emblemático de éxito en el crédito. El análisis de su accionar financiero permitirá abrir el esquema interpretativo y plantear otras alternativas de ingreso para los actores de la época y exponer la relevancia que tuvo el préstamo en la economía salteña tardovirreinal $[1]$ El origen social de Moldes lo distingue del conjunto de prestamistas de la época e invita a analizar su trayectoria económica.

Se embarcó como criado desde Cádiz, condición social poco honorable según parámetros del antiguo régimen, arribó a Buenos Aires, luego se trasladó a la ciudad de Salta, plaza en la cual se afincó definitivamente, construyó una nueva identidad, alcanzó el ascenso social y el progreso económico. Fue una de las más de 100000 almas que se aventuraron en cruzar el Atlántico a lo largo del siglo xvIII, motivados por hallar en estos reinos americanos, una mejor calidad y condición de vida, escasos en sus lugares de nacimientos (Pérez, 2012).

Fue en su despliegue como prestamista, el rasgo que lo diferenció de sus contemporáneos dedicados al rubro ganadero, la invernada y remesa de mulas al Alto Perú. Las fuentes consultadas permiten conocer hoy que el origen de la fortuna que administró este hombre al final de su vida provino de su exitosa actividad en el crédito.

Desde su afincamiento en Salta, se constituyó en un lucrativo prestamista de envergadura transregional. La red de circulación de sus préstamos, en bienes y metálico, rebasó los muros de dicha ciudad y la jurisdicción de la Intendencia de Salta del Tucumán. Como rasgo significativo debe indicarse que sus principales deudores no se encontraron al norte, en el espacio altoperuano sino al sur, en Buenos Aires.

De modo paradójico, pese al relevante patrimonio consolidado, su nombre no figura en las exposiciones históricas escritas abocadas al estudio de la elite económica salteña del siglo xviII, ni en calidad de comerciante, prestamista o propietario rural. Tampoco por la riqueza atesorada $2^{2}$ De allí, que el presente artículo se proponga también brindar respuestas al porqué de su ausencia.

Metodológicamente, para abordar el itinerario como acreedor de Juan Antonio Moldes, se consultó y confrontó un corpus documental, que incluye correspondencias privadas, testamento, tasaciones de bienes y obligaciones de pago registradas en los protocolos notariales, resguardados en el Archivo Histórico de Salta (en adelante AHs) y en la Biblioteca Atilio Cornejo. En las próximas líneas se desarrollarán las singularidades del prestamista Juan Antonio Moldes.

\footnotetext{
${ }^{1}$ Partimos de la premisa que los mercados son entendidos como construcciones sociales. No se mueven como leyes naturales impuestas por sí mismas a los seres humanos, sino, antes bien, constituyen constructos humanos determinados por valores, costumbres, instituciones sociales, económicas y políticas (Marichal, Topik, Frank, 2017, p. 17).

${ }^{2}$ A partir del análisis de las testamentarias y con base en el análisis de las explotaciones rurales, Mata (2000) identificó las principales fortunas de Salta de la segunda mitad del siglo xviII. Ubicó en el primer puesto a Nicolás Severo de Isasmendi, último gobernador intendente con un caudal de 111483 pesos; en segundo lugar, a Victorino Martínez de Tineo, exgobernador de Tucumán y presidente de la Audiencia de Charcas, con un patrimonio de 91173 pesos y, en tercer lugar, a Arias Rengel Apolinario con 41920 pesos. Para su jerarquización consideró a "todos aquellos propietarios que poseían bienes por un monto superior a los 5000 pesos eran estimados en la documentación como 'españoles', es decir 'blancos' y pertenecientes a troncos familiares de antiguo linaje” (pp. 183-184). Si consideramos estas proyecciones, la fortuna que Moldes declaró poseer en su testamento de 73000 pesos, sería la tercera más importante de Salta.
} 


\section{Juan ANTONio Moldes: De SERVIDOR DOMÉSTICO A EXITOSO PRESTAMISTA VIRREINAL}

Moldes fue oriundo del arzobispado de San Pedro de Villalonga, Galicia, hijo de Plácido Moldes y Bernarda de Arcaballas. Arribó a Buenos Aires en 1765, cuando esta aún pertenecía al virreinato de Perú y luego se trasladó a Salta en 1767, ciudad de la gobernación de Tucumán. Cruzó el Atlántico en calidad de criado del comerciante peninsular Juan Pérez Sánchez, junto a su par sevillano Martín González 3

Su llegada a tierras americanas se produjo en el contexto de las migraciones de peninsulares hacia las Indias, motivados por una mejor calidad y condición de vida, impulsados por el entorno favorable creado por las reformas borbónicas y el relativo crecimiento económico general por el que atravesó el espacio en esos años (Gelman, 2014). 4

Desconocemos cuál fue el móvil que lo llevó hasta Salta una vez que descendió en Buenos Aires, tampoco sabemos sobre el paradero de su par criado ni de su amo comerciante al que sirvió en alta mar. Las fuentes son más fiables y permiten seguir su trayectoria una vez que se afincó como residente en la ciudad de Salta, plaza en la cual abrazó el éxito económico y construyó una nueva posición e identidad social diferente con la cual desembarcó en América (Justiniano, Madregal y Anachuri, 2018).

La ciudad de Salta fue un centro mercantil significativo en toda la etapa virreinal y en relación con otras ciudades colindantes como Tarija, Jujuy, Tucumán, Catamarca, Santiago del Estero y el distrito de la Puna, es la que registró mayor actividad comercial y financiera (Acevedo, 1965,

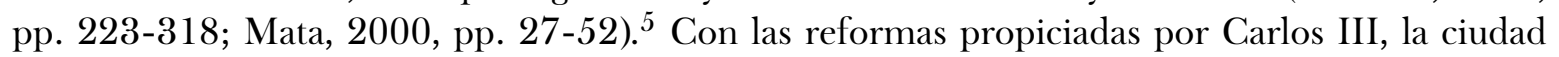
se constituyó en capital de la Intendencia de Salta del Tucumán, en división administrativa y territorial que controló entre sus límites jurisdiccionales los anteriores centros urbanos, a los cuales se sumaría San Ramón de la Nueva Orán; abarcó una enorme extensión geográfica y heterogénea realidad socioeconómica. Con este nuevo reposicionamiento administrativo pasó a ser sede del gobernador intendente y despacho de las cajas reales mayores ${ }^{6}$ Ello confirma la gravitante posición económica frente a las demás urbes vecinas.

Según Santilli (2013) las reformas borbónicas impactaron de modo positivo en toda la región. El crecimiento económico fue impulsado por la legalización comercial del puerto de Buenos Aires y la creación del virreinato del Río de la Plata; esta bonanza relativa se evidencia en el incremento de la actividad comercial, productiva y demográfica. López de Albornoz (2002) remarcó que la

${ }^{3}$ Juan Pérez Sánchez, Contratación, 5507, N.3, R.39 - 1 Recto - Imagen núm. 1, en Archivo General de Indias (en adelante AGI). Según Dubert (2005), los criados de los territorios de la monarquía hispánica procedían de familias con escasas posibilidades económicas. La falta de recursos para subsistir era una de las razones que movilizó a jóvenes de ambos sexos a dedicarse al servicio, actividad contemplada poco honorable y destino de los hijos de jornaleros, inquilinos y propietarios agrícolas pobres con ansias de superación. La licencia de embarque otorgada por la Casa de Contratación de Sevilla no le permitía a ninguno de los tres quedarse, todos debían regresar al cabo de tres años.

${ }^{4}$ La América borbónica ofreció muchos incentivos a los españoles peninsulares, tales como el disfrute de cargos públicos, las posibilidades mercantiles, la demanda de oficios especializados. Moldes fue uno de los 55000 viajeros que cruzaron legalmente el Atlántico (Marqués, 1993). El número asciende a 120000 si son consideradas las salidas legales e ilegales entre 1700 y 1824 desde el puerto de Cádiz (Martínez, 1994, pp. 165-168).

${ }^{5}$ Las operaciones crediticias de Moldes se desarrollan tempranamente cuando aún Salta formaba parte de la gobernación de Tucumán y se extiende cuando esta se constituye en la capital de la Intendencia de Salta del Tucumán.

${ }^{6}$ Sobre la administración y situación de las cajas reales a fines del siglo xvIII, véase Gavira (2016). 
Intendencia de Salta del Tucumán experimentó un mayor dinamismo, se acrecentaron los circuitos comerciales y las actividades productivas, reconoció el periodo 1785-1789, como el de mayor crecimiento económico de esta división administrativa creada por los borbones.7 7

La plaza salteña, constituida ahora en capital de la flamante intendencia, no quedó exenta de este florecimiento económico. Gracias a su estratégica ubicación geográfica se constituyó en un polo articulador entre el centro minero potosino con Buenos Aires, la cual lejos de ocupar una posición marginal como la que tuvo en la centuria anterior; en esta etapa se constituyó en un centro portuario de envergadura que articuló mercados distantes, exportó e importó bienes (Jumar, 2008), asimismo las transformaciones económicas globales a causa de la industrialización inglesa incidió en la significativa función que comenzó a tener este puerto (Camarda, 2016).

Para este periodo, los yacimientos potosinos y novohispanos aumentaron significativamente su producción argentífera (Bakewell, 2000, pp. 49-88). La plata que irradió de estos centros mineros se constituyó, no solamente en una mercancía altamente apreciada, sino en una de las monedas metálicas de mayor difusión global del antiguo régimen (Marichal, Topik y Frank, 2017, pp. 3841). América exportó durante la etapa moderna más de 80 \% de la plata que circuló a nivel mundial (Flynn y Giraldez, 1995).

Estas monedas inyectaron a economías europeas, asiáticas, orientales, bálticas, rusas e indias, circularon vía Pacífico y Atlántico, constituyéndose en el motor de los intercambios intercontinentales ${ }^{8}$ Palma y Silva (2016) subrayaron que el efecto de los metales preciosos americanos fue seis veces mayor al descubrimiento de nuevas rutas comerciales, estos aumentos sustanciales de dinero metálico persistieron durante mucho tiempo y llevaron a un aumento exógeno del PIB real de las economías globales, el cual alcanzó su punto más alto con un aumento promedio de $1.3 \%$ anual.

Desde temprano la historiografía económica reconoció la relevancia del crédito en la economía virreinal. Desde esta perspectiva analítica, Garzón Maceda (1968, pp. 27-35) señaló a la escasez crónica como uno de los factores principales que promovieron su desarrollo; reconoció también la "penuria de monedas metálicas" e identificó la concomitancia de una economía natural y otra monetaria. Por su parte, Braudel (2014, pp. 56-65) subrayó que, en esa economía moderna metálica, el crédito y el dinero se constituyeron en instrumentos que dominaron los intercambios. Bernal (2000) caracterizó al crédito como una necesidad insoslayable de medio de pago. De igual forma, Pérez (1989) relacionó el aumento de la producción metalífera con la expansión del crédito. Wasserman (2018, pp. 23-30) remarcó al crédito como un factor condicionante para la consolidación de la economía de la Buenos Aires del siglo XviI.

Juan Antonio Moldes desplegó sus actividades mercantiles en ese entorno favorable económicamente para la Intendencia de Salta del Tucumán en el virreinato del Río de la Plata. A diferencia de sus contemporáneos, dedicados al comercio mular y la producción rural, concentró sus inversiones en préstamos transregionales.

$\mathrm{Su}$ itinerario en el crédito también arroja luz sobre el espacio de acción de estos comerciantes salteños que superó el tradicional espacio peruano articulado por el polo potosino. Se vuelca desde temprano hacia el Atlántico, la mayoría de sus transferencias las realizó en Buenos Aires. Suponemos que antes de su llegada a Salta en 1767, estableció vínculos con los comerciantes porteños a quienes representó una vez afincado en la plaza salteña. Alonso Vázquez fue uno de ellos, quien

\footnotetext{
${ }^{7}$ Sobre la construcción, características y expansión del concepto de reformas borbónicas como categoría analítica e historiográfica, véase Sánchez (2016).

${ }^{8}$ Sobre la relevancia del Pacífico en el comercio global y la incidencia del comercio asiático en Perú y Nueva España, véase Bonialian (2012).
} 
al momento de transferir el poder que anteriormente había puesto en otras personas al prestamista salteño en 1767, destacó su honradez y eficacia en el ámbito de los negocios: "Revocando como revoco otros cualesquiera así especiales como generales que habría conferido a otras personas, asimismo, por esto ante bien dejarles como les dejo en su buena reputación y fama y en dicha conformidad otorgo y conozco por el presente instrumento que doy todo mi poder el que por derecho se requiere y necesario sea a Juan Antonio Moldes del comercio y almacén en esta Ciudad de Salta.'9

Reconocidos comerciantes y estancieros de Salta también depositaron potestad en Moldes apenas arribado a la gobernación del Tucumán. Su introducción en la plaza local incluyó rápidamente el desplazamiento de otros agentes del ámbito comercial.

En 1770 Cayetano Viniegra, quien registró todo su crédito mercantil en el rubro mular, administrador de temporalidades, alcalde de segundo voto del cabildo capitalino y emparentado con Nicolás Severo de Isasmendi, quien sería el último gobernador de la Intendencia de Salta del Tucumán, otorgó el poder que anteriormente asignó a su hermano Juan Viniegra, al recién llegado Juan Antonio Moldes ${ }^{10}$ Su vínculo será dilatado en el tiempo y revistió diferentes momentos. Años más tarde, en 1777, compartieron en sociedad una empresa redistributiva de efectos de castilla junto a Juan de la Centolla, Sanforizo Rioja y Francisco Maurín.11

En 1779, Viniegra se constituyó en deudor de Moldes por un préstamo monetario de 15000 pesos que este último otorgó a favor de él y sus socios, Nicolás Severo de Isasmendi, Gregorio Martearena, Felipe Mendiolaza y Manuel Salvador Fernández.

Moldes formalizó el préstamo como obligación de pago ante el escribano público del número Antonio Gil Infante en la ciudad de Salta. En esta escritura notarial los deudores se reconocieron como tal y manifestaron cancelar el crédito en un plazo de tres años. Por cada lustro se obligaron "con su persona y los bienes habidos por haber" a entregar 5000 pesos más los intereses correspondientes según "práctica y estilo del comercio". Ante el notario y los testigos presentes manifestaron: "Debemos pagar llanamente y sin pleito alguno al expresado Juan Antonio Moldes o quien su dicho representante en cualquier manera que sea a saber los expresados 5000 pesos cada un año por el término de tres contenidos desde el 5 de febrero de 1779 en delante de cuya cantidad se constituyen líquidos llanos y verdaderos deudores. 12

Moldes entretejió redes de corresponsales transregionales que se encargaron en disipar y agilizar la cancelación de sus préstamos transferidos en otros puntos del virreinato, la cual podía surtirse en oro, plata sellada y labrada, piñas, joyas, mercaderías, esclavos, frutos, géneros de Castilla o de la tierra, ropas y diferentes especies de valor. Si el caso lo requería, el representante o apoderado debía llegar a instancias judiciales ante el deudor moroso. Agentes cercanos a su entorno y de reconocida buena reputación en el ámbito de los negocios ejercieron la recaudación de sus préstamos otorgados en ciudades distantes a Salta.

Manuel Antonio Tejada fue uno de estos corresponsales. La relación entre ambos expresa familiaridad, seguridad y perdurabilidad en el tiempo. Tejada fue tesorero de Salta, cabildante, comerciante y prestamista, que tempranamente estableció ligámenes con notables mercaderes

\footnotetext{
${ }^{9}$ Protocolos, núm. 161, carpeta 15, f. 21 . AHs.

${ }^{10}$ Protocolos, núm. 150, carpeta 5, f. 260. AHs.

${ }^{11}$ En el documento expresaron "año de alcabala terrestre varios tercios fardos y cajones que dichos individuos internaron a esta ciudad con legítimo despacho de la de Buenos Aires después de a ver satisfecho allí la alcabala marítima”. Protocolos, [s. n.], carpeta 14, f. 63. AHs.

12 Protocolos, número 150 , carpeta 15 , f. 12 . AHs.
} 
porteños como Belgrano Pérez, se emparentó con Moldes al contraer nupcias con Catalina Fernández Arias, hermana de María Fernanda Loria Arias Velázquez, mujer que eligió Moldes como su consorte ${ }^{13}$ En 1771, Juan Antonio Moldes indicaba a su apoderado Tejada y José Estévez las instancias para exigir la cancelación de los préstamos que aún no habían sido cancelados:

convengan deban y puedan hacer los pedimentos, requerimientos, citaciones y protestaciones necesarias, presenten escritos, escrituras [...] testimonios, certificaciones, escrituras y demás probanzas [...] pidan prisiones, excusiones, mandamientos de solturas, embargos y desembargos, remate de bienes pidiendo su posesión a los rematados [...] apelen y supliquen y sigan las apelaciones y supliquen por todo grado e instancias, hasta su final conclusión [...] saquen y ganen las provisiones con fuerzas como otros despachos a mi favor 14

La perdurabilidad en la relación entre ambos sujetos se evidencia en dos momentos. En 1799 al compartir una sociedad mercantil junto a Francisco Maurín y Mateo Gómez Zorrilla, comerciantes y prestamistas salteños, y Juan Nadal y Guarda, administrador de temporalidades y apoderado de Moldes en Salta ${ }^{15}$ más tarde en 1804 Tejada fue albacea de tercer voto en el testamento de Moldes.

En Buenos Aires, ciudad en la cual concentró gran parte de sus préstamos, Antonio Obligado y Thomas de Insua, fueron los agentes en quienes depositó su poder para la cobranza de los empréstitos que allí otorgó 16 Ambos fueron sujetos influyentes y conocidos del mundo mercantil rioplatense.

Obligado fue un comerciante-hacendado de distinguida participación en la política mercantil porteña del siglo xviII, miembro honorario del gremio de los hacendados y el cabildo de Buenos Aires (Mir, 2013). Thomas de Insua fue un comerciante porteño (Bolsi, 2013) quien supo mantener una relación prolongada con su apoderado, en 1790 participó como intermediario de una red mercantil que unió Cádiz, Filipinas, Buenos Aires y administró Moldes desde Salta ${ }^{17}$

La aparición de deudores en Buenos Aires invita a revisar aquellas afirmaciones historiográficas, que marcaron una situación de dependencia por parte de los comerciantes del interior respecto de unas cuantas líneas de crédito habilitadas por los comerciantes porteños (Gelman, 1990). Obsérvese que la cadena espacial de circulación de los préstamos de Moldes no se concentró en el espacio peruano, sino al sur, en la capital del virreinato del Río de la Plata (véase cuadro 1). El importe total adeudado por los porteños en 1772 asciende a casi 30000 pesos.

Muchos de los prestatarios radicados en Buenos Aires son representativos del mundo mercantil porteño de la segunda mitad del siglo XviII. Manuel Caviedez al momento de la tasación ya es un comerciante instalado de la plaza, también dedicado al préstamo de dinero y bienes. Manuel Rodríguez de la Vega, de actividad política en la ciudad, fue elegido en diferentes oportunidades por sus pares para diversas gestiones, tales como la instalación del Tribunal del Consulado, o manifestar la posición del comercio ante el virrey. Bernardo Sancho Larrea también ejerció la labor

\footnotetext{
${ }^{13} \mathrm{El}$ matrimonio con los Arias Velázquez permitió a ambos peninsulares introducirse al círculo social donde la sociedad coetánea los reconoció como beneméritos y distinguidos (Lloveras y Medardo, 2004). Sobre la relevancia del comerciante Belgrano Pérez, véase Gelman (1996).

${ }^{14}$ Protocolos, núm. 161, carpeta 11, f. 165. AHs.

${ }^{15}$ Protocolos, núm. 189, f. 19, año 1799. AHs.

${ }^{16}$ Protocolos, núm. 147, carpeta 14, f. 42. AHs.

${ }^{17}$ Carpeta 5. Biblioteca Atílio Cornejo.
}

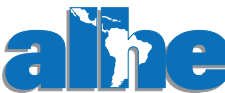




\section{CUADRO 1. PRÉSTAMOS DE JUAN ANTONIO MOLDES A VECINOS DE BUENOS AIRES, 1772}

\begin{tabular}{lc}
\hline Deudores de Buenos Aires & $\begin{array}{c}\text { Monto en pesos } \\
\text { reales del ocho }\end{array}$ \\
\hline Manuel Caviedes & 8930 \\
Manuel Rodríguez de La Vega & 5555 \\
Bernardo Sancho Larrea & 4809 \\
José Luis Feduche & 1243 \\
Antonio Miguel Folch & 1300 \\
Jacobo Felipe Gómez & 1068 \\
Francisco Balvinos & 500 \\
Vicente Andino & 330 \\
Pedro Ceferino San Martin & 166 \\
Juan Mojaime & 734 \\
Manuel Escalada & 795 \\
Gonzalo Doblas & 691 \\
Sancho Quiñones & 323 \\
Juan Lesica & 337 \\
Manuel Baldan & 0.94 \\
Saturnino Álvarez & 1 \\
Manuel Antonio Tejada & 800 \\
Monto total & 2784 \\
\hline
\end{tabular}

Fuente: elaboración propia con base en Tasación de Bienes, carpeta 8, 1772. Biblioteca Atilio Cornejo.

pública, y junto con Rodríguez de la Vega participó de la demanda del comercio de la época para la instalación de un consulado en Buenos Aires. Gonzalo Doblas estaba dedicado al préstamo y al comercio de efectos y géneros de Castilla (Schlez, 2016). También, puede mencionarse a Juan Lezica, reconocido por Socolow (1978) y Halperín (1972, p. 42) como importante comerciante porteño y propietario de una de las fortunas más grandes del virreinato con 160000 pesos.

El espacio de circulación de sus transferencias crediticias se amplía aún más si consideramos a sus deudores en Chile y Cochabamba, en la Intendencia de Santa Cruz. En Chile, fue Manuel Conchas quien contrajo un préstamo por 300 pesos, su deudor en la ciudad altoperuana fue el comerciante Juan Carillo y Albornoz por 4600 pesos, crédito que invirtió para financiar sus ventas de efectos de castilla en la plaza cochabambina (véase cuadro 2) 18

El monto total adeudado por los salteños es de casi 20000 pesos. Con algunos de estos prestatarios estableció vínculos que superó lo meramente económico (véase cuadro 3 ).

Nicolás Ignacio de Aramburu fue maestre de campo de la plaza salteña y apoderado de Moldes; años más tarde se asocian para el remate del año de alcabalas en 1805.19 Juan Antonio Quiroz y Juan Mojaime, dos comerciantes de efectos ultramarinos que depositaron su representación en Moldes. Francisco Gavino Arias fue un importante estanciero salteño quien figura con la deuda

${ }^{18}$ Protocolos, núm. 150, carpeta 15, f. 7 . AHS.

${ }^{19}$ Protocolos, núm. 199, carpeta 15, f. 61 . AHs. 
CUADRO 2. PRESTATARIOS EN CHILE Y COCHABAMBA, 1772

\begin{tabular}{lrllr}
\hline \multicolumn{1}{c}{ Deudor } & Capital prestado & Residencia & Destino del préstamo & Tasa de interés anual \\
\hline Manuel Conchas & 300 & Chile & Comercio & 5 \\
Juan Carillo & 4600 & Cochabamba & Efectos de castilla & 5 \\
\hline
\end{tabular}

Fuente: elaboración propia con base en Tasación de Bienes, ccarpeta 8, 1772, y Protocolos Notariales. Biblioteca Atílio Cornejo. Protocolos Notariales, letra M. Archivo Histórico de Salta.

más significativa de 1900 pesos ${ }^{20}$ Resalta también en la lista de los deudores salteños familiares de Moldes. Pedro y Valenciano Arias Velázquez fueron tíos de María Fernanda Loria Arias Velázquez, su cercanía se evidencia al constituirse en testigos de la escritura de la última voluntad de su acreedor en 1804.

Los créditos que figuran en los cuadros 1,2 y 3 fueron registrados en su tasación de 1772 (véase Apéndice, cuadro 6). Las transferencias crediticias que realizó ante un escribano figuran en los protocolos notariales salteños como obligación de pago (véase Apéndice, cuadro 7) ${ }^{21}$ Esta forma de registrar formalmente una operación de crédito, ante un notario, le ofreció garantías legales, una protección relativa, ante un deudor desconocido en un mercado de crédito especulativo e inseguro con altos índices de riesgos financieros (Caballero, 2011; Quintanar, 2017, pp. 157-199).

Según Wasserman (2010), la obligación de pago posibilitó la configuración de compromisos crediticios normalmente vinculados al gran comercio, se constituyó en uno de los principales instrumentos notariales utilizados para realizar operaciones crediticias, constituía un contrato por el cual el deudor se obligaba a reintegrar a su acreedor un monto dinerario determinado en un plazo establecido, se definía las garantías materiales ofrecidas, junto con las cláusulas y penalidades (Wasserman, 2018 p. 167).

El crédito notariado se gravaba con hipotecas, bienes raíces, títulos, efectos, pulperías, etc. En su estudio sobre la relevancia de las redes crediticias en el comercio novohispano, Quintanar (2017, pp. 157-199) manifestó que la presentación de garantías no necesariamente mantuvo una relación directa con el monto prestado, sino que pareció estar ligada con el cálculo del riesgo según la capacidad de pago del deudor y el destino del dinero.

Formalmente los escribanos del antiguo régimen participaban en distintos grupos de profesionales; mientras que los escribanos públicos del número desarrollaban el ejercicio de sus tareas en un territorio asignado, a los escribanos reales no se les asignaba territorio y sus tareas eran en principio secretariales. El escribano fungió como parte contractual, instituía y proveía la información al prestamista sobre su futuro prestatario (Wasserman, 2010; 2018, p. 147).

${ }^{20}$ Protocolos, núm. 169, carpeta 15, f. 2. AHs.

${ }^{21}$ A finales del siglo xx, Gelman (1990) definió la formalización ante un escribano como un instrumento legal que garantizó el cobro de la deuda. Para Tedesco (2001) fue una promesa de pago extendida por el deudor al acreedor, en el cual el primero confiesa que debe real y verdaderamente y se obliga a pagarlo. La renovación historiográfica amplió el campo de indagación al sujeto y las prácticas, ocupado en aspectos cualitativos sobre agentes y agencia. Wasserman (2010) rescató la participación del escribano ante quien se realizaba la obligación de pago. Identificó la existencia de diversos instrumentos escritos para formalizar las deudas, tales como escrituras públicas, cedulas, vales, recibos, cartas, libranzas, libros de cuenta, etc. Distinguió entre instrumentos públicos y privados; los primeros fueron realizados ante escribanos, cabildo u otra institución competente regia, los segundos eran realizados por particulares, sin intervención de agentes oficiales. Subrayó que las escrituras públicas fueron las que dinamizaron mayor capital (Wasserman, 2018, pp. 147-153). 


\section{CUADRO 3. DEUDORES DE MOLDES EN LA CIUDAD DE SALTA}

\begin{tabular}{|c|c|}
\hline Deudores & $\begin{array}{l}\text { Monto en pesos } \\
\text { de real del ocho }\end{array}$ \\
\hline Nicolás Ignacio de Aramburu & 307 \\
\hline Juan Alonso Arroyo & 206 \\
\hline José Colunga & 336 \\
\hline $\begin{array}{l}\text { Cristóbal Gordillo } \\
\text { y Jacinto Antonio Carro }\end{array}$ & 216 \\
\hline Bernardo Valdez & 1319 \\
\hline Juan Mójame & 2063 \\
\hline Miguel Antonio Alurralde & 23.70 \\
\hline José Antonio Alurralde & 324.70 \\
\hline Mateo Salcedo & 0.70 \\
\hline Ramón Antonio Gil Taboada & 160.40 \\
\hline Pedro Montero & 461 \\
\hline Antonio Quiroz & 314.20 \\
\hline José Martínez & 300 \\
\hline Ignacio Fernández & 38.70 \\
\hline Vicente Jiménez Cisneros & 77.30 \\
\hline Antonio Cornejo & 0.94 \\
\hline Joseph Estévez & 303 \\
\hline José Javier Dorado & 9.210 \\
\hline Francisco Gavino de Arias & 1983 \\
\hline Antonio Ruiz Carabajal & 9023 \\
\hline Juan Sandoval & 12.70 \\
\hline José Hinojosa & 407.40 \\
\hline Diego Reyes & 0.12 \\
\hline Marcos Velasco & 1093 \\
\hline Pablo Vidal & 72.30 \\
\hline Valenciano Arias & 14.30 \\
\hline Pedro Arias & 108.30 \\
\hline José Antonio Cruz & 33.60 \\
\hline Monto total & 19292 \\
\hline
\end{tabular}

Fuente: elaboración propia con base en Tasación de Bienes de Juan Antonio Moldes, carpeta 8, 1772. Biblioteca Atilio Cornejo.

El notario público de número Antonio Gil Infante fue a quien Moldes acudió con mayor frecuencia para registrar sus transacciones crediticias realizadas en la ciudad de Salta, posiblemente los negocios en común que mantuvieron explicarían la inclinación del prestamista por este notario. 22

\footnotetext{
${ }^{22}$ En términos porcentuales podemos indicar que más de 60 \% lo realizó en esta escribanía, el resto ante el escribano José Rodríguez, quien es contemporáneo a Gil Infante.
} 
Analizar los protocolos de escribano es importante y enriquecedor para abordar las prácticas económicas en comunidades que dieron gran relevancia a la cultura escrita, como fuente legitimadora de la monarquía hispánica, instrumento de poder de unos frente a otros y marco jurídico para emprender cualquier tipo de actividad ${ }^{23}$ A pesar de la diversidad de instrumentos empleados al momento de registrar una deuda, las obligaciones de pago se caracterizaron por asentar transferencias de montos significativos. Estas escrituras habrían de legitimar el compromiso cuyo cumplimiento fuese reclamado si el caso lo demandaba.

La información que otorgaba el notario permitió al prestamista evaluar rigurosamente y seleccionar a aquellos prestatarios que se hallaban en mejores condiciones para acceder al crédito y poder devolverlo en el plazo fijo pactado. Juan Antonio Moldes otorgó préstamos, comúnmente a sujetos acaudalados, dedicados a actividades redituables, de reconocida participación política en la ciudad local y distinguido capital social.

En 1771 el alcalde de segundo voto del cabildo local, Pedro Lucas Allende, comerciante y estanciero en el valle de Lerma, dedicado a la invernada y remesa de mulas al Alto Perú, requirió un préstamo por 5761 pesos, para el flete de sus tropas de mulas a Perú, obligándose a devolverlo a finales del mes de diciembre del año en curso ${ }^{24}$ Ese mismo lustro, Antonio Ruiz Carabajal, hombre dedicado a la producción y el comercio ganadero, también demandó de los préstamos de Juan Antonio Moldes, en aquella oportunidad lo hizo por 12080 pesos, para adquirir efectos de castilla, responsabilizándose de su rembolso en un plazo fijo de seis meses ${ }^{25}$

En 1775 Francisco Gavino Arias Rengel, hacendado salteño que ejerció numerosos cargos militares en la gobernación del Tucumán ${ }^{26}$ pidió un préstamo por 8700 pesos con el compromiso de cancelarlo en un plazo fijo de seis meses mediante la entrega de 500 quintales de jabón; aclaró que "de no saldar la deuda en el plazo estipulado queda obligado a pagar todo el resto del total a fines de febrero o principio de marzo del próximo año en plata, moneda corriente" 27

El comerciante de efectos ultramarinos Francisco Lima solicitó un crédito a su favor por 3200 pesos, se obligó a retribuirlo en dos partes: una primera mitad del monto en cuatro meses y la segunda en ocho ${ }^{28}$ Juan Miguel Salazar recibió a crédito 800 pesos para abrir una botica y vender efectos de castilla en la ciudad de San Salvador de Jujuy, centro urbano colindante a la ciudad de Salta 29

El señor Francisco Luján fue otro comerciante mular y productor rural que solicitó un crédito a Moldes por 1500 pesos a un plazo fijo de siete meses, el deudor manifestó ante el escribano que asentó la operación, que en caso de no corresponder el pago en el plazo pactado "han de correr en adelante los intereses correspondientes conforme a estilo y práctica del comercio sin prejuicio de lo ejecutivo en cuanto al dinero principal con los gastos y prejuicios que en la cobranza se le causasen y perjudiquen al dicho acreedor" 30

\footnotetext{
${ }^{23}$ Sobre la cultura escrita en el antiguo régimen, véase Gómez (2010).

${ }^{24}$ Protocolos, núm. 135, carpeta 12, f. 89. AHs.

${ }^{25}$ Protocolos, núm. 134, carpeta 11-A, f. 3. AHs.

${ }^{26}$ Sobre Gavino Arias Rengel véase Lloveras y Medardo (2003).

${ }^{27}$ Protocolos, núm. 142, carpeta 12, f. 26 . AHS.

${ }^{28}$ Protocolos, núm. 146, carpeta 14, f. 185 . AHS.

${ }^{29}$ Protocolos, núm. 155, carpeta 15, f. 10. AHS.

${ }^{30}$ Protocolos, núm. 158, carpeta 12, f. 1. AHs.
} 
El interés, definido como el precio que paga el prestatario por el uso del fondo prestable, fue una ganancia considerable de los prestamistas, aunque no siempre se constituyó en el único criterio para la colocación de recursos crediticios (Wasserman, 2015, pp. 77-86). Generalmente se expresó como un porcentaje anual entre 5 y $7 \%$, aunque también se manifestó como un tanto por ciento mensual o quinquenal (Chacón, 2010) ${ }^{31}$ Los diferentes tipos de intereses dependieron de la duración y riesgo del préstamo, mientras más largo fue el tiempo del empréstito y su riesgo financiero más elevado, mayor fue la tasa de interés.

Aun cuando no todos los préstamos notariados por Moldes registran el interés, algunos sí. Por ejemplo, el que transfirió en 1774 a Diego Lorenzo Ríos y Ramón Ugarteche, a su favor por 3000 pesos, ambos dedicados al comercio ultramarino, se obligaron a pagar el préstamo en un plazo fijo de ocho meses, con un interés de $6 \%$ anual, es decir, que abonaron quince pesos mensuales por esta unidad de crédito 32

El segundo caso es el del transportista tucumano Francisco Javier Sánchez de Lamadrid; en este caso, le prestó la suma de 1000 pesos plata, que debía ser devuelta a $8 \%$ anual y en seis meses. Es decir que se abonó 6.67 pesos de interés por cada mes a favor del prestamista salteño. En ambas oportunidades la tasa de interés superó a la moralmente aceptada de la época.

Desde un punto de vista comparado para estos años, economías como las de Bogotá, Medellín, Popayán o Nueva España, mostraron la misma tendencia en la tasa de intereses, al igual que la Intendencia de Salta del Tucumán en el virreinato del Río de la Plata, se fijó comúnmente a $5 \%$ anual, tasa porcentual éticamente admisible. Torres (2014) indicó que a finales del siglo XvIII las tasas de interés prosiguieron unívocamente a disminuir en todo el espacio hispanoamericano, enfatizó en dos posibles causas: ocultamiento usurero del préstamo e impacto del libre comercio.

Las operaciones crediticias que Juan Antonio Moldes registró ante un escribano en la plaza salteña, como obligación de pago, entre 1771 hasta 1803, en su conjunto superó la cantidad de 72000 pesos, la que se incrementaría si computamos los intereses correspondientes de cada unidad de crédito asentado de esta forma (véase cuadro 4).

Juan Antonio Moldes destinó una porción significativa de sus activos financieros al crédito a lo largo de su vida. En 1772 declaró un patrimonio neto de 48000 pesos, de los cuales 30200 pesos se encontraban dispersos en préstamos. En su testamento redactado en 1804, atestiguó una fortuna conyugal de 73000 pesos, más de la mitad aún estaba invertida en créditos que no habían sido cancelados, con un líquido de 50000 pesos. La suma total que este hombre transfirió a crédito a lo largo de su vida asciende a 178000 pesos, monto que habilitó en préstamos monetarios o físicos. ${ }^{33}$ El promedio de los montos que acreditó rondó los 2500 pesos, significativo para el periodo 34

\footnotetext{
${ }^{31}$ Wasserman (2015) sostiene que la tasa de interés de $5 \%$ anual era generalizada dentro de las colonias españolas, mientras que, en la metrópoli, 3 por ciento.

${ }^{32}$ Protocolos, núm. 146, carpeta 14, f. 12. AHs.

${ }^{33}$ Este cálculo se realizó con base en la cartera total reconstruida por Moldes. Se sumó la totalidad de sus transferencias crediticias registradas en los distintos instrumentos empleados, la tasación, los créditos notariados y los que figuran en el documento de su última voluntad.

${ }^{34}$ Wasserman (2014) reconoce como montos abultados aquellos que giran entre 800 y 5000 pesos, cuya finalidad era el comercio mayorista. Otra comparación puede encontrarse en los salarios relativos de la época. Por ejemplo, para tener una referencia general, el sueldo anual del intendente gobernador en la Intendencia de Salta del Tucumán era de 3800 pesos a finales del siglo XviII. Libro 189, caja 2, Hacienda. AHS.
} 


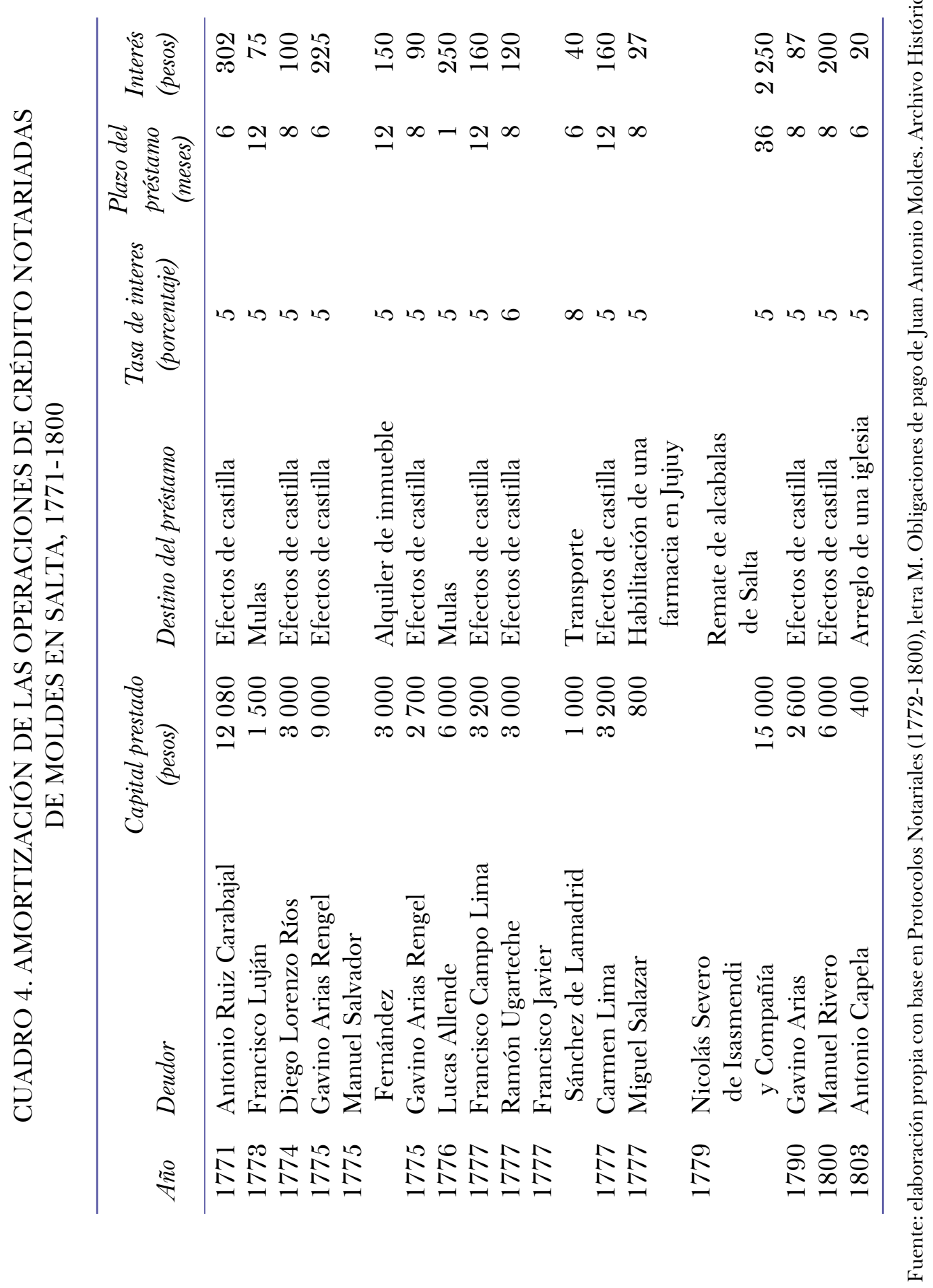


Su exitoso y redituable derrotero como prestamista le permitió incrementar notablemente su fortuna. Desde su afincamiento en Salta, en 1767, hasta la fecha en que redactó su testamento, 1804, su patrimonio neto creció $52 \%$ en términos relativos ${ }^{35}$ Ahora bien, del análisis global de su actuar como prestamista se pueden conjeturar diferentes momentos, respecto a las cantidades en dinero transferido y operaciones realizadas, expensa a las situaciones coyunturales del entorno económico y político en que desplegó sus actividades.

En toda la década de 1770 distribuyó créditos de modo constante, por significativas cifras que habilitó tanto a productores rurales como comerciantes transregionales. Es sugerente que durante el decenio de 1780 no figura en los protocolos notariales locales ni en otras fuentes que registren habilitaciones crediticias realizadas en la ciudad de Salta; posteriormente, la etapa de 1790 está determinada por el contexto bélico que enfrentó a la corona española e inglesa y trastocó negativamente los intercambios transoceánicos (Mazzeo, 1999, pp. 1-17).

La presencia de barcos ingleses en los mares aumentó la especulación y el riesgo en el envío de productos desde España a puertos americanos; esta situación de permanente hostilidad perjudicó a aquellos comerciantes transoceánicos que adquirían mercancías en las fábricas de Cádiz o Inglaterra para luego venderlos en sus tiendas locales de América. El mismo Moldes vio afectado sus negocios ultramarinos por esta contienda internacional.

El 2 de octubre de 1798 Francisco Javier Sanfis, agente encargado en adquirir y remitir los géneros desde Cádiz, manifestó su preocupación por la hostil situación a causa de la coyuntura bélica que bloqueo los puertos peninsulares y obstruyó la habitual vía atlántica, Islas CanariasCabo Verde-Cabo de San Agustín-Montevideo y Buenos Aires. En una misiva comunicaba a su sucio Moldes:

[...] no puedo remitir a usted nada de lo que me tiene pedido y tengo la mayor parte comprada porque seguramente sería perderlo todo a causa de estar bloqueado este puerto con 22 navíos de guerra ingleses y muchas fragatas y los mares cubiertos de corsarios a no ser que usted quiera correr estos riesgos y me lo ordene expresadamente [...] aunque nosotros nos hallamos con muchísimos géneros apropiados y otros muchísimos pedidos a las fabricas para que sean de los más selectos no me determino a hacer las remesas algunas ni de cuenta de vuestra merced ni de la nuestra, pues es mejor tener los géneros existentes que aventurarnos a perderlo todo, porque al fin aunque no se gane no se pierde, espero vuestra merced tendrá a bien esta determinación, atendidas las insistencias del días, y que aquí tenemos la cosa presente y según se ve operamos como en asunto propio pero si la corte determina dar combói suficiente hasta el Río de la Plata (como se tiene pretendido) procurare en este caso remitir a vuestra merced su dinero empleado para que de este modo no se perjudique con la demora, en la inteligencia que si el combói no es más que hasta la altura de las Canarias no remitiré nada porque después quedan que pasar muchos riesgos como son las Islas de Cabo Verde, Cabo de San Agustín, y altura de Janeiro donde los ingleses es regular tengan los navíos y fragatas de guerra para interceptar los barcos nuestra que descargan y varían para el sur $[\ldots]$ [6]

\footnotetext{
${ }^{35}$ Se calculó el patrimonio neto. Se tomó como dato el capital inicial que declaró en la tasación de 1772 y su capital final que justificó en su última voluntad.

${ }^{36}$ Correspondencias de Juan Antonio Moldes, carpeta 5. Biblioteca Atílio Cornejo.
} 
Durante los años que duró el enfrentamiento transoceánico, Moldes enfatizó su participación como fabricante regional. En 1798 celebró la fundación de una fábrica productora de lienzos en sociedad con Mariano Antezana, comerciante de Cochabamba en la Intendencia de Santa Cruz. Los nuevos socios manifestaron ante el escribano público:

[...] por la presente otorgan que fundan y establecen la compañía en los términos condiciones fama y manera siguiente: primeramente que el fondo de ella se debe componer de la cantidad de 48000 pesos introduciendo cada socio el capital de 20400 pesos cuya cantidad a regir por mano del contenido de don Mariano Antezana invirtiéndolos inicialmente en la compra y escogió los algodones en la costa conduciéndolos a Cochabamba vendiéndose allí, bien sea en la propia especie o bien después de reducidos a lienzos o tucuyos según mayor cuenta haga y ofrezca el tiempo [...] ${ }^{37}$

Finalizada la guerra entre las monarquías, las transferencias crediticias de Moldes se recuperaron, aunque no con la frecuencia que lo habría caracterizado años previos. Juan Antonio Moldes hacia 1800, era un hombre veterano y más sedentario en sus negocios, pese a realizar pocas operaciones crediticias, estas mantuvieron montos semejantes a las anteriores, con intereses elevados y plazos fijos que excedieron los 24 meses (véase gráfica 1).

Decidido a asegurar su fortuna, el futuro y la posición de sus herederos en la comunidad salteña contemporánea, redactó su testamento en 1804 ante el escribano José Rodríguez. En este documento manifestó los saldos de sus deudores (véase cuadro 5 y Apéndice, cuadro 8). Reconoció, además como débitos incobrables aquellos préstamos que no fueron devueltos, los cuales adeudaban en su conjunto 2610 pesos.

Juan Antonio Moldes mantuvo vínculos mercantiles o familiares con la mayoría de sus deudores consignados en su testamentaria. Encabeza la lista Francisco Javier Sanfis, hombre que se encargó de remitir productos desde Cádiz a Moldes para surtir su tienda en la plaza salteña ${ }^{38}$ En segundo lugar, Gerardo Posse, reconocido comerciante y transportista tucumano (Bolsi, 2013) le administró dinero al prestamista salteño en Buenos Aires 39

Antonio Martínez San Miguel, quien figura con un total adeudado de 29000 pesos, se emparentó con Juan Antonio Moldes al casarse con su hija, Josefa Moldes. Antonio Chavarría, a quien podemos considerar como uno de los “nuevos actores" salteños de principios del siglo xix, también se vinculó matrimonialmente con una hija de la familia Moldes, Manuela Moldes fue la elegida como su consorte. El matrimonio con las jóvenes hijas de su acreedor permitió a los dos comerciantes peninsulares posicionarse en la sociedad coetánea y administrar las transacciones crediticias de su suegro en la capital del virreinato del Río de la Plata.

La fortuna que construyó a lo largo de su vida fue dividida en tercios y repartida entre sus hijos, según consta en testamento. Falleció el 16 de mayo de 1807 a los 66 años, momentos antes de que la monarquía -a la cual juró fidelidad "manifestando siempre los sentimientos más sinceros de un fiel vasallo y buen servidor del rey- implosionara y entrara en crisis 40 Sus descendientes vivieron

${ }^{37}$ Carpeta 19, Protocolos, núm. 184, f. 19. AHs.

${ }^{38}$ Correspondencias, caja 7, carpeta 5 . Biblioteca Atilio Cornejo.

${ }^{39}$ Testamento de Juan Antonio Moldes, carpeta 8. Biblioteca Atilio Cornejo.

${ }^{40} \mathrm{El} 20$ de noviembre de 1804, los ministros generales de la Real Hacienda ponían de relevancia su satisfacción respecto al cargo de visitador general de la Aduana de Salta que ejerció Juan Antonio Moldes durante doce años, destacando que "Juan Antonio Moldes ha desempeñado a satisfacción de estos reales oficios y el público sin sueldo gratificante ni 


\section{GRÁFICA 1. MOVIMIENTOS EN LOS VOLÚMENES ACREDITADOS POR JUAN ANTONIO MOLDES (1767-1807) (PESOS REALES DEL OCHO)}

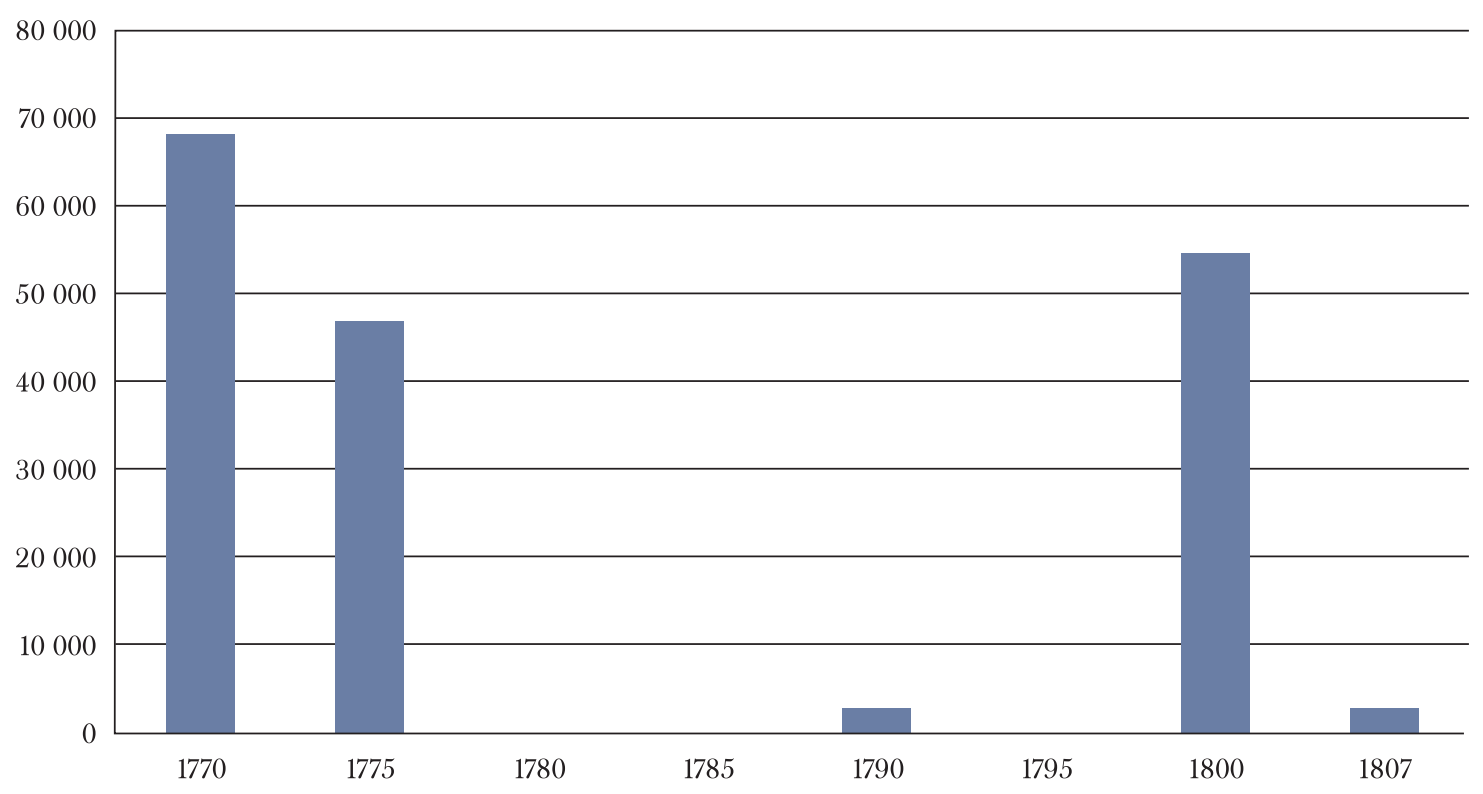

Fuente: elaboración propia con base en créditos registrados en su tasación (1772), Protocolos de Escribanos, letra M (1771-1800). AHS. Testamento, 1804, carpeta 8. Biblioteca Atilio Cornejo.

una nueva etapa política, algunos de ellos abrazaron la causa revolucionaria y tuvieron finales trágicos, como José Moldes, otros quedaron sumidos en las facciosas luchas que envolvió a la ciudad de Salta tras la revolución de 1810, ninguno continuó los negocios de su padre, sus hijas emparentadas con comerciantes españoles experimentaron las disquisiciones de los empréstitos forzosos impuestos por los flamantes Estados para mantener económicamente la causa revolucionaria.

\section{Conclusiones}

El itinerario como prestamista de Juan Antonio Moldes pretende abrir el esquema interpretativo, además de plantear otros ejes analíticos a los propuestos por la historiografía económica regional. No se trata, desde luego, en desacreditar los planteamientos de este modo de historiar el pasado salteño, sino de exponer la relevancia que ocupó el crédito en la concreción de las fortunas de los partícipes de la época en particular y en la economía salteña en general, plantear otra alternativa de riqueza y complejizar la actividad económica de este periodo finivirreinal.

El derrotero aquí propuesto es un caso emblemático de éxito en el préstamo, aunque no es el único. La dedicación mercantil de este hombre distó en demasía a la de sus pares dedicados a la producción rural y el comercio mular con el Alto Perú. Su inversión en préstamos transregionales

ayuda a costa del empleo de vuestra majestad para tenerlo fijado esta real aduana y así mismo ha entregado en esta tesorería el donativo que expresa manifestando siempre los sentimientos más sinceros de un fiel vasallo y buen servidor del rey". Carpeta 7. Biblioteca Atilio Cornejo. 


\section{CUADRO 5. DEUDORES DE MOLDES CONSIGNADOS EN SU TESTAMENTARIA, 1804}

\begin{tabular}{|c|c|c|}
\hline Deudor & Residencia del deudor & Monto (pesos) \\
\hline Francisco Javier Sanfis & Cádiz & 13693 \\
\hline Gerardo Posse & $\begin{array}{l}\text { San Miguel } \\
\text { de Tucumán }\end{array}$ & 4600 \\
\hline Antonio Martínez San Miguel & Buenos Aires & 2000 \\
\hline Antonio Martínez San Miguel & Buenos Aires & 27787 \\
\hline Antonio Chavarría & Buenos Aires & 1902 \\
\hline José María La Hora & Salta & 900 \\
\hline Santiago Costas (párroco) & Salta & 7 \\
\hline Mercedes Surlín & Salta & 40 \\
\hline María Elena Toledo Gallo & Salta & 70 \\
\hline \multicolumn{2}{|c|}{ Total, adeudado } & 51000 \\
\hline
\end{tabular}

a No se computó aquellos préstamos que aparecen como débitos incobrables.

Fuente: elaboración propia con base en Testamento de Juan Antonio Moldes, carpeta 8. Biblioteca Atilio Cornejo.

permitió un incremento sustancial en su patrimonio neto y el goce de una de las fortunas más holgadas de la Intendencia de Salta del Tucumán, en los espacios más australes de la monarquía hispánica, lo que vuelve aún más singular su trayectoria (véase apéndice, cuadro 9).

Sus redes de circulación crediticia no se ubicaron al norte, en el tradicional espacio peruano, sino al sur en Buenos Aires. Su vinculación con importantes mercaderes porteños respalda aquellos estudios que advierten una conexión temprana entre Salta y la capital del virreinato del Río de la Plata desde la segunda mitad del siglo XviI e invita a debatir aquellas afirmaciones historiográficas que sostuvieron la dependencia relativa por parte de los comerciantes del interior de unas cuantas líneas de crédito por los grandes empresarios porteños.

Salta fue una plaza financiera activa de la flamante Intendencia de Salta del Tucumán, su vinculación a un centro minero de envergadura global como lo fue Potosí y un puerto que empezó a cobrar relevancia tras la industrialización del norte Atlántico como el de Buenos Aires, estimuló el despliegue del crédito como principal medio de pago en esa economía moderna metálica, la cual quedó exenta de las situaciones coyunturales propias de una economía global que enfrentaría periodos de incertidumbres y especulaciones en las últimas dos décadas del siglo xviII, ante la revolución industrial inglesa, los conflictos bélicos internacionales, previo al demonio de la inestabilidad institucional, social y política que se desató tras la implosión monárquica, su posterior crisis y las revoluciones del siglo XIX. 
APÉNDICE

\section{CUADRO 6. PRÉSTAMOS OTORGADOS POR JUAN ANTONIO MOLDES REGISTRADOS EN TASACIÓN PATRIMONIAL, 1772}

\begin{tabular}{|c|c|}
\hline Deudores & Monto (real del ocho) \\
\hline Manuel Caviedes & 8930 \\
\hline Manuel Rodríguez de la Vega & 5555 \\
\hline Bernardo Sancho Larrea & 4809 \\
\hline José Luis Feduche & 1243 \\
\hline Antonio Miguel Folch & 1300 \\
\hline Jacobo Felipe Gómez & 1068 \\
\hline Francisco Balbino & 500 \\
\hline Vicente Andino & 330 \\
\hline Pedro Ceferino San Martín & 166 \\
\hline Juan Mojaime & 734 \\
\hline Manuel Escalada & 795 \\
\hline Gonzalo Doblas & 691 \\
\hline Sancho Quiñones & 323 \\
\hline Juan Lezica & 337 \\
\hline Manuel Baldan & 1 \\
\hline Saturnino Álvarez & 1 \\
\hline Manuel Antonio Tejada & 800 \\
\hline Manuel Conchas & 300 \\
\hline Juan Carillo y Albornoz & 4600 \\
\hline Nicolás Ignacio de Aramburu & 307 \\
\hline Juan Alonso Arroyo & 206 \\
\hline José Colunga & 336 \\
\hline Cristóbal Gordillo y Jacinto Antonio Carro & 216 \\
\hline Bernardo Valdez & 1319 \\
\hline Juan Mójame & 2063 \\
\hline Miguel Antonio Alurralde & 24 \\
\hline José Antonio Alurralde & 325 \\
\hline Mateo Salcedo & 1 \\
\hline Ramón Antonio Gil Taboada & 160 \\
\hline Pedro Montero & 461 \\
\hline Antonio Quiroz & 314 \\
\hline José Martínez & 300 \\
\hline Ignacio Fernández & 39 \\
\hline Vicente Jiménez Cisneros & 77 \\
\hline Antonio Cornejo & 1 \\
\hline Joseph Estévez & 303 \\
\hline José Javier Dorado & 92 \\
\hline Francisco Gavino de Arias & 1983 \\
\hline
\end{tabular}




\begin{tabular}{lr} 
Antonio Ruiz Carabajal & 923 \\
Juan Sandoval & 13 \\
José Hinojosa & 407 \\
Diego Reyes & 0 \\
Marcos Velasco & 1093 \\
Pablo Vidal & 72 \\
Valenciano Arias & 14 \\
Pedro Arias & 108 \\
José Antonio Cruz & 34 \\
\hline
\end{tabular}

Fuente: Tasación de Bienes, carpeta 8, 1772. Biblioteca Atilio Cornejo.

\section{GUADRO 7. PRÉSTAMOS OTORGADOS POR JUAN ANTONIO MOLDES REGISTRADOS EN PROTOCOLOS NOTARIALES (1773-1803)}

\begin{tabular}{lrr}
\hline Deudores & Monto (real del ocho) & Años \\
\hline Antonio Ruiz Carabajal & 12080 & 1773 \\
Francisco Luján & 1500 & 1773 \\
Diego Lorenzo Ríos & 3000 & 1774 \\
Gavino Arias Rengel & 9000 & 1775 \\
Manuel Salvador Fernández & 3000 & 1775 \\
Gavino Arias Rengel & 2700 & 1775 \\
Lucas Allende & 6000 & 1776 \\
Francisco Campo Lima & 3200 & 1777 \\
Ramón Ugarteche & 3000 & 1777 \\
Francisco Javier Sánchez de Lamadrid & 1000 & 1777 \\
Carmen Lima & 3200 & 1777 \\
Miguel Salazar & 800 & 1777 \\
Nicolás Severo de Isasmendi y Compañía & 15000 & 1779 \\
Gavino Arias & 2600 & 1790 \\
Manuel Rivero & 6000 & 1800 \\
Antonio Capella & 400 & 1803 \\
\hline
\end{tabular}

Fuente: Sección Protocolos Notariales, Obligaciones de pago, letra M, 1772-1803. Archivo Histórico de Salta.

\section{LISTA DE REFERENCIAS}

Abad, L. V. (1993). Nuevas formas de inmigración: un análisis de las relaciones interétnicas. Política y sociedad, 12, 45-60.

Acevedo, E. O. (1965). La Intendencia de Salta del Tucumán en el Virreinato del Río de la Plata. Mendoza: Universidad Nacional de Cuyo/Instituto de Historia.

Bakewell, P. (1990). La minería hispanoamericana colonial. En L. Bethell (ed.), América Latina colonial: economía (3a ed., Vol. 3, pp. 49-88). Barcelona: Crítica. 


\section{CUADRO 8. PRÉSTAMOS OTORGADOS POR JUAN ANTONIO MOLDES REGISTRADOS EN TESTAMENTO, 1804}

\begin{tabular}{lr}
\hline Deudores & Monto (real del ocho) \\
\hline Francisco Javier Sanfis (Cádiz) & 13693 \\
Gerardo Posse & 4600 \\
Antonio Martínez San Miguel & 2000 \\
Antonio Martínez San Miguel & 27 \\
Antonio Chavarría & 1902 \\
José María La Hora & 900 \\
Santiago Costas & 7 \\
Mercedes Surlín & 40 \\
María Elena Toledo Gallo & 70 \\
Francisco Antonio Llanos & 300 \\
Nicolás Gonzales (finado) & 189 \\
Tomas Ducal & 964 \\
Antonio Zamora & 32 \\
Juan Matías de Ibarra & 29 \\
Luis García de Castro & 170 \\
Francisco Torres, El Relojero & 6 \\
Tomasa Fernández & 17 \\
Melchor Ibáñez & 3 \\
Juan de Elina & 147 \\
Martín Outes & 10 \\
Rafael Bachier (finado) & 19 \\
Juan Cabrera & 61 \\
María Simona Orellana & 9 \\
\hline
\end{tabular}

Nota: no se incluyen las operaciones crediticias registradas en Buenos Aires, ni operaciones posteriores a 1804, fecha de su testamento.

Fuente: Carpeta 8, Testamento de Juan Antonio Moldes, 1804. Biblioteca Atilio Cornejo.

Bernal, A. M. (2000). Introducción. En A. M. Bernal (ed.), Dinero, moneda y crédito en la monarquía hispánica: actas del Simposio Internacional "Dinero, Moneda y Crédito: de la Monarquía Hispánica a la Integración Monetaria Europea”, Madrid, 4-7 de mayo de 1999 (pp. 7-11). Madrid: Marcial Pons/Fundación ICO.

Bolsi, F. (2013). Familia, estrategias de reproducción social y comercio de exportación en Tucumán, Argentina, 1780-1820. Una aproximación a partir de la familia Posse. Anuario de Estudios Americanos, 70(1), 129-156. DOI: 10.3989/aeamer.2013.1.05

Bonialian, M. A. (2012). El Pacífico hispanoamericano: política y comercio asiático en el imperio español, 1680-1784: la centralidad de lo marginal. México: Colegio de México.

Braudel, F. (2014). La dinámica del capitalismo (6a ed.). México: Fondo de Cultura Económica.

Caballero, T. C. (2011). Créditos, monedas, comerciantes y prestamistas. En el mercado financiero en Barranquilla entre 1849 y 1903. Historia Caribe, 6(18), 145-164. 


\section{CUADRO 9. LOS DIEZ PRINCIPALES PRESTAMISTAS DE LA CIUDAD DE SALTA SEGÚN SUS VOLUMENTES TOTALES ACREDITADOS (1770-1810)}

\begin{tabular}{lc}
\hline Nombre y apellido & $\begin{array}{c}\text { Monto total } \\
\text { transferido a crédito }\end{array}$ \\
\hline Juan Antonio Moldes & 172000 \\
Manuel Antonio Tejada & 153911 \\
Domingo Funes & 108681 \\
Cayetano Viniegra & 77196 \\
Francisco Maurín & 74142 \\
Mateo Gómez Zorrilla & 48821 \\
Thomas Allende & 46192 \\
Francisco de la Torre & 30313 \\
Pedro de Elexalde & 25073 \\
Lorenza de la Cámara & 19600 \\
\hline
\end{tabular}

Fuente: elaboración propia con base en Protocolos de Escribanos, 1770-1810: carpeta 11, protocolo 134; carpeta 12 , protocolos 135, 136, 137, 138; carpeta 13, protocolos 141, 142; carpeta 14, protocolos 144, 145, 146,147; carpeta 15, protocolos 148, 149, 150; carpeta 16, protocolos 158, 159, 160, 161; carpeta 18; protocolos 175; carpeta 19, protocolo 191; carpeta 20, protocolos 198, 203, 204, 205, 206, 213, 229. Archivo Histórico de Salta. Salta-Capital.

Camarda, M. (2016). El comercio ultramarino de cueros salidos por el complejo portuario rioplatense en la segunda mitad del siglo xviII. Fronteras de la Historia, 21(1), 182-208.

Chacón, M. (2010). El crédito en las transacciones de bienes y servicios durante el perído colonial. Costa Rica: Centro de Investigaciones Históricas de América Central. Recuperado de http://repositori os.cihac.fcs.ucr.ac.cr/repositorio/handle/123456789/71

Dubert, I. (2005). Criados, estructura económica y social y mercado de trabajo en la Galicia rural a finales del Antiguo Régimen. Historia Agraria. Revista de Agricultura e Historia Rural. Sociedad Española de Historia Agraria, 35, 9-26.

Flynn, D. O. y Giráldez, A. (1995). Born with a "Silver Spoon": The Origin of World Trade in 1571. Journal of World History, 6(2), 201-221.

Frías, B. (1924). Tradiciones históricas. Buenos Aires: Jesús Menéndez.

Garzón, C. (1968). Economía del Tucumán: economía natural y economía monetaria, siglos XVI, хVII y X

Gavira, M. C. (2016). El visitador general del Virreinato del Río de La Plata, Diego de la Vega, y las irregularidades en las Cajas Reales Altoperuanas (1802). América Latina en la Historia Económica, 23(1), 90. DOI: 10.18232/alhe.v23i1.65

Gelman, J. D. (1990). Venta al contado, venta a crédito y crédito monetario en América colonial: acerca de un gran comerciante del virreinato del Río de la Plata. Jahrbuch für Geschichte Lateinamerikas, 27(1). DOI: 10.7788/jbla-1990-0105

Gelman, J. D. (1996). De mercachifle a gran comerciante: los caminos de ascenso en el Río de la Plata Colonial. La Rábida: Universidad Internacional de Andalucía.

Gelman, J. D. (2014). Los cambios en la economía atlántica entre los siglos XVII y XIX. Desarrollo capitalista, globalización y desigualdad en América Latina. Nuevo mundo mundos nuevos, 14. DOI: $10.4000 /$ nuevomundo.66288 
Gómez, M. G. (2010). Del ministerio de papeles al procedimiento. En C. Garriga Acosta (ed.), Historia y constitución: trayectos del constitucionalismo hispano (pp. 347-378). México: Centro de Investigación y Docencia Econmica/El Colegio de México /El Colegio de Michoacán/Escuela Libre de Derecho/Proyecto de Investigaciones Hicoes/Universidad Autónoma de Madrid.

Halperin, T. (1972). Revolución y guerra: Formación de una elite dirigente en la Argentina criolla. Buenos Aires: Siglo XXI.

Jumar, F. A. (2008). El primer boom de la exportación de cueros y la sociedad local. Río de la Plata a fines del siglo XVII y comienzos del siglo XVIII. En XXI Jornadas de Historia Económica. Caseros, Argentina. Recuperado de http://www.memoria.fahce.unlp.edu.ar/trab_eventos/ev.712 /ev.712.pdf

Justiniano, M. F., Madregal, C. M. y Anachuri, M. G. (2019). De criado a comerciante global y funcionario regio (Salta, Buenos Aires, Cádiz, Filipinas, 1764-1804). Revista de Indias, 277.

Justiniano, M. R. y Tejerina, M. (2012). Salta y la nación a comienzos del siglo XIX: un análisis en clave historiográfica. En Primeras Jornadas Nacionales de Historiografía (pp. 418-430). Córdoba: Río Guarto.

Lloveras, G. y Medardo, D. (2003). Formación y consolidación de una familia de elite en Salta: el caso de los Arias Rengel (siglos XVII y XVIII). Revista Escuela de Historia, 2(1), 9.

Lloveras, G. y Medardo, D. (2004). Estudio de dos familias de élite en Salta durante el período colonial: el caso de los Arias Velazquez y Arias Rengel. Revista Escuela de Historia, 1(3).

López, C. (2002). Tiempos de cambio: producción y comercio en Tucumán (1770-1820). Andes, 13.

Marichal, C., Topik, S., Frank, Z. L. y Zamudio, M. A. (2017). Introducción. En C. Marichal, S. Topik y Z. L. Frank (eds.), De la plata a la cocaína: cinco siglos de historia económica de América Latina, 1500-2000 (pp. 9-37). México: Fondo de Cultura Económica.

Martínez, C. (1994). La emigración española a América, 1492-1824. Colambre: Archivo Indiano.

Mata, S. (1996). El crédito mercantil. Salta a fines del siglo XviII. Anuario de Estudios Americanos, 53(2), 147-171. DOI: 10.3989/aeamer.1996.v53.i2.419

Mata, S. (2000). Tierra y poder en Salta. El noroeste argentino en vísperas de la independencia. En S. Mata (ed.), Tierra y poder en Salta: el noroeste argentino en vísperas de la independencia (pp. 27-29; 181-242). Sevilla: Diputación de Sevilla.

Mazzeo, C. A. (1999). El comercio internacional en la crisis de la independencia de América. Lima-Cádiz 1783-1825. En C. A. Mazzeo (ed.), Los comerciantes limeños a fines del siglo xVIII. Capacidad y cohesión de una elite, 1750-1825 (pp. 1-17). Lima: Pontificia Universidad Católica del Perú, Dirección Académica de Investigación.

Mir, L. B. (2013). Mesta e intereses ganaderos en el Buenos Aires tardocolonial (1772-1794). Quinto Sol, (3), 9-28. DOI: 10.19137/qs.v3i0.638

Palma, N. y Silva, A. C. (2016). Spending a Windfall: American Precious Metals and Euro-Asian Trade 1531-1810. GGDC Research Memorandum, 165, 1-49. DOI: 10.2139/ssrn.2877128

Paz, G. (1999). A la sombra del Perú: mulas, repartos y negocios en el norte argentino a fines de la colonia. Boletín del Instituto de Historia Argentina Dr. Emilio Ravignani, 20, 45-68.

Pérez, M. A. (2012). De Europa al Nuevo Mundo: la inmigración europea en Iberoamérica entre la Colonia tardía y la Independencia. Introducción al dossier. Nuevo Mundo Mundos Nuevos. Recuperado de http://www.memoria.fahce.unlp.edu.ar/trab_eventos/ev.712/ev.712.pdf 
Pérez, P. (1989). El crecimiento economico novohispano durante el siglo XVIII: Una revision. Revista de Historia Económica / Journal of Iberian and Latin American Economic History, 7(1), 69-110. DOI: $10.1017 / \mathrm{S} 0212610900001142$

Quintanar, I. (2017). Una aproximación al estudio de las redes crediticias novohispana: El consulado de la ciudad de México y el depósito irregular, siglos XVIII-XIx. En G. del Valle y A. Ibarra (eds.), Redes, corporaciones comerciales y mercados hispanoamericanos en la economía global, siglos XVII-XIX (pp. 157-199). México: Instituto de Investigaciones Dr. José María Luis Mora/Consejo Nacional de Ciencia y Tecnología.

Sánchez-Albornoz, N. (1965). La saca de mulas de Salta al Peru, 1778-1808. Anuario del Instituto de Investigaciones Históricas, (8), 261-312.

Sánchez-Santiró, E. (2016). Las reformas borbónicas como categoría de análisis en la historiografía institucional, económica y fiscal sobre Nueva España: orígenes, implantación y expansión. Historia Caribe, 11(29), 19-51.

Santilli, D. (2013). ¿Perjudiciales o Beneficiosas? La discusión sobre el impacto económico de las reformas borbónicas en Buenos Aires y su entorno. Fronteras de la Historia, 18(2), 247283.

Schlez, M. M. (2016). La medición de la ganancia mercantil en el Río de la Plata colonial: el caso de Diego de Agüero y Compañía (Río de la Plata, 1770-1820). Revista de Indias, 76(268), 751-788. DOI: 10.3989/revindias.2016.023

Seldon, A. y Pennance, F. G. (eds.). (1983). Diccionario de economía: una exposición alfabética de conceptos económicos y su aplicación. Barcelona: Orbis.

Socolow, S. M. (1978). The Merchants of Buenos Aires 1778-1810: Family and commerce. Cambridge: Cambridge University Press. DOI: 10.1017/CBO9780511759826

Tedesco, É. (2001). El crédito de origen eclesiástico en la ciudad de Córdoba, 1800-1830. Cuadernos de Historia. Serie economía y sociedad, 4, 239-276.

Torres, J. V. (2014). Tasas de interés y desempeño económico: el crédito comercial en Santafé de Bogotá, 1760-1810. América Latina en la Historia Económica, 21(3), 9-45. DOI: 10.18232/alhe.v21i3.577

Wasserman, M. L. E. (2010). El rol social de un contrato económico: crédito notariado y recursos relacionales en Buenos Aires, siglo XVII. Anuario del Centro de Estudios Históricos, 10(1), 115140.

Wasserman, M. L. E. (2014). Diseño institucional, prácticas y crédito notarial en Buenos Aires durante la primera mitad del siglo XVII. Investigaciones de Historia Económica - Economic History Research, 10(1), 1-12. DOI: 10.1016/j.ihe.2013.10.001

Wasserman, M. L. E. (2015). La mediación notarial en la interacción económica: confianza, información y conexiones en la temprana Buenos Aires. Prohistoria, 18(24), 69-100.

Wasserman, M. L. E. (2018). Las obligaciones fundamentales: crédito y consolidación económica durante el surgimiento de Buenos Aires. Buenos Aires: Prometeo Libros. 